Volumetric method.
Carbon....................... $\begin{gathered}\text { Gravimetric after } \\ \text { titration. }\end{gathered}$
$\begin{array}{ll}0.89 & 0.88 \\ 0.97 & 0.97 \\ 2.73 & 2.75 \\ 2.75 & 2.80 \\ 3.17 & 3.20 \\ 3.58 & 3.59 \\ 3.84 & 3.83\end{array}$

Many chemists prefer burning the carbonaceous residue, and I have found that graphite is rapidly oxidized if filtered on a small Gooch crucible and then without drying or removing the asbestos, the Gooch is immediately placed bottom $u p$ in the combustion crucible. Fifteen minutes burning will be ample time using about $60 \mathrm{cc}$. oxygen gas per minute.

I wish to avail myself of this opportunity to thank Mr. H. A. Schwartz, the Secretary of the Indiana Section of the American Chemical Society, for investigating synthetic mixtures of various amounts of dried, and also freshly precipitated barium carbonate, when mixed with various amounts of standard barium hydroxide and titrated with acid.

The Aupperle crucible is described in Iron Age of October 6, I904; abstracted in Iron and Steel Magazine, December, 1904.

LABORATORY OF E. C. ATKINS \& CO.

INDIANAPOLIS, IND.

\title{
THE DETERMINATION OF CARBON IN IRON AND STEEL BY DIRECT IGNITION WITH RED LEAD. ${ }^{1}$
}

BY ChaRLES MORRIS JOHNSON. Received January 22, 1906.

THE writer's experience with this method for the determination of carbon, together with some notes on what led to its adoption for routine combustion analysis, may prove of interest.

The solution of steel drillings containing large percentages of chromium, tungsten or molybdenum in double chloride of copper and potassium causes more or less loss of carbon as hydrocarbon. Especially sensitive to such loss are the carbides that are separated by the double chloride from steels in which are Io or I 2 per cent. of molybdenum together with several per cent. of chromium.

These carbides may lose some of the carbon by contact with

${ }^{1}$ A preliminary paper was read at the December meeting of the Pittsburg Section of the American Chemical Society. 
dilute acid, or with the oxygen of the air during washing with suction or during the subsequent drying of the carbide at the temperature of boiling water.

In the spring of 1900 , the writer made an analysis for carbon of a steel containing 3.8 per cent. of chromium, applying the ordinary method of dissolving the borings in acid double chloride of copper and potassium, filtering on an asbestos plug, washing the carbide residue alternately with distilled water, and a mixture of one part of hydrochloric acid and twenty parts of water. The residue was then washed with water, alone, to remove the acid. After drying the washed carbide in a water oven, it was burned with purified oxygen in a red hot porcelain tube containing about $13 \mathrm{~cm}$. of copper oxide. The products of the combustion were passed through granulated zinc of 20-mesh fineness, then through anhydrous calcium chloride, and then through phosphoric anhydride. The purified carbon dioxide was absorbed and weighed in potash bulbs. Duplicate analyses by this method failed to check.

A series of analyses of these borings were made. The acid wash when used was alternated with distilled water and the washing was then completed with distilled water, alone, to remove acid.

\begin{tabular}{|c|c|c|}
\hline $\begin{array}{c}\text { Kind of wash. } \\
\text { I ............. } 20 \text { parts } \mathrm{H}_{2} \mathrm{O} \text { to I part } \mathrm{HCl}\end{array}$ & $\begin{array}{c}\text { Number } \\
\text { washings. } \\
20\end{array}$ & $\begin{array}{c}\text { Carbon found. } \\
\text { Per cent. } \\
\text { I. } 65\end{array}$ \\
\hline $2 \ldots \ldots \ldots \ldots$ I00 parts $\mathrm{H}_{2} \mathrm{O}$ to I part $\mathrm{HCl}$ & 20 & 1.52 \\
\hline $3 \ldots \ldots \ldots \ldots$ IOo parts $\mathrm{H}_{2} \mathrm{O}$ to I part $\mathrm{HCl}$ & 2 & 1.909 \\
\hline $4 \ldots \ldots \ldots \ldots$ Ioo parts $\mathrm{H}_{2} \mathrm{O}$ to I part $\mathrm{HCl}$ & 2 & 1.943 \\
\hline
\end{tabular}

In August, I902, the process used in the foregoing, (3) and (4), was applied to a steel containing 4 per cent. of chromium and 4 per cent. of molybdenum with the following absence of agreement:

First analysis gave 1.28 per cent. carbon.

Second analysis gave 1.53 per cent. carbon.

Third analysis gave 1.33 per cent. carbon.

Fourth analysis gave 1.29 per cent. carbon.

The thought occurred that perhaps the carbide obtained from molybdenum steel gives up part of its carbon as hydrocarbon on being brought into contact with the air during stirring. No heat was applied to hasten the solution at any time. A number of trial analyses were made in which the time of stirring was varied and also the acidity of the copper and potassium chloride solution. 
In the following, 2 grams of the drillings were dissolved in I $80 \mathrm{cc}$. of the double chloride solutions. By acid solution is meant a solution prepared by dissolving 600 grams of double chloride of copper and potassium in $\mathrm{I} 500 \mathrm{cc}$. of distilled water acidulated with $175 \mathrm{cc}$. of concentrated hydrochloric acid. By nearly neutral solution is meant the same as the acid solution except that but $25 \mathrm{cc}$. of concentrated hydrochloric acid were added to the I $500 \mathrm{cc}$. of distilled water.

The neutral solution consisted of 600 grams of the double chloride, I $500 \mathrm{cc}$. of distilled water and no acid. The results obtained are given in the following table:

Steer Containing 4 Per Cent. Molybdenum and 4 Per Cent.

\section{CHROMIUM.}

\begin{tabular}{|c|c|c|c|c|}
\hline Kind of steels. & kind of solvent. & $\begin{array}{l}\text { Time of } \\
\text { stirring. } \\
\text { Minutes. }\end{array}$ & $\begin{array}{l}\text { Time in the } \\
\text { solvent with } \\
\text { no stirring. } \\
\text { Hours. }\end{array}$ & $\begin{array}{l}\text { Percentage of } \\
\text { carbon found. }\end{array}$ \\
\hline No. I steel & acid & 20 & & 1.53 \\
\hline No. I steel & ، & 20 & & I. 48 \\
\hline No. I steel & “ & IO & & 1.64 \\
\hline No. I steel & " & & I 2 & I. 49 \\
\hline No. I steel & " & & 24 & 1.52 \\
\hline No. I steel & nearly neutral & 8 & & 1.60 \\
\hline No. I steel & " $" ،$ & 8 & & 1.55 \\
\hline No. I steel & acid & 3 & & 1.60 \\
\hline No. I steel & neutral & 6 & & 1.593 \\
\hline No. I steel & "r & 6 & & I. 606 \\
\hline No. 2 steel & " & 4 & & I. 679 \\
\hline No. 2 steel & " & 6 & & I. 734 \\
\hline No. 2 steel & acid & 4 & & 1.758 \\
\hline No. 2 steel & ، & 4 & & I. 66 \\
\hline
\end{tabular}

A combustion of the 4 per cent. chromium, 4 per cent. molbydenum steel (No. 2), by the red lead process described below yielded r.734 per cent. carbon.

An examination of the foregoing table shows that both in the No. 2 and the No. I steels the highest result was obtained when the acid solvent was used and also the lowest results.

Short stirring gave better agreements than the longer periods of stirring but had evidently not eliminated all of the causes of loss. Perhaps there is loss of carbon when the carbide is being dried in the water-oven. Further, it is practically impossible to regulate the suction so as to expose the residues, during washing, to exactly the same amount of air in each analysis.

Two grams of the No. 2 steel were stirred twenty minutes with 
I $80 \mathrm{cc}$. of the acid solution, then transferred to the asbestos plug. Air was next drawn through the residue for fifty minutes; the amount of carbon obtained was I.347 per cent. Two determinations of the same steel were made with sixty minutes' stirring but with the least possible exposure to suction; I. 63 per cent. and I. 68 per cent. carbon were found. In view of these results the practice was adopted of always keeping a layer of distilled water over the carbide during the washing. As soon as one layer, or covering of water, was drawn off, another was immediately supplied.

This treatment was applied to a group of ingots containing I I per cent. of molybdenum and some chromium. The neutral solution gave the higher results as shown by the following table:

$\begin{array}{cc}\text { Acid solvent. } & \text { Neutral carbon. } \\ \text { Per cent carbon. } & 0.60 \\ 0.52 & 0.56 \\ 0.46 & 0.59\end{array}$

The same process of short stirring and least possible exposure of the carbide residue to air by suction, together with the use of a neutral solvent, was adopted for a series of ingots containing I 2 per cent. of molybdenum and several per cent. of chromium. It failed almost completely. For convenient comparison the results obtained in these latter experiments are shown in a column parallel to those obtained, at a later date, from the same samples by the red lead combustion method.

One well-known laboratory obtained 0.72 per cent. carbon and another, equally experienced, reported 0.64 per cent. carbon on the S. H. S. sample.

This untrustworthiness of the double chloride process for separating carbon in steel of high molybdenum and chromium content led to a search for some method of obtaining the percentage of carbon by burning the entire substance. Having about this time noted Brearley and Ibbotson's statement that steel drillings that will pass a 2o-mesh sieve and have been mixed with about three times their weight of red lead can be decarbonized in a red hot porcelain tube, it was decided to attack the molybdenum steel in this manner. The results obtained from the molybdenum steels have been already given and need no comment. 


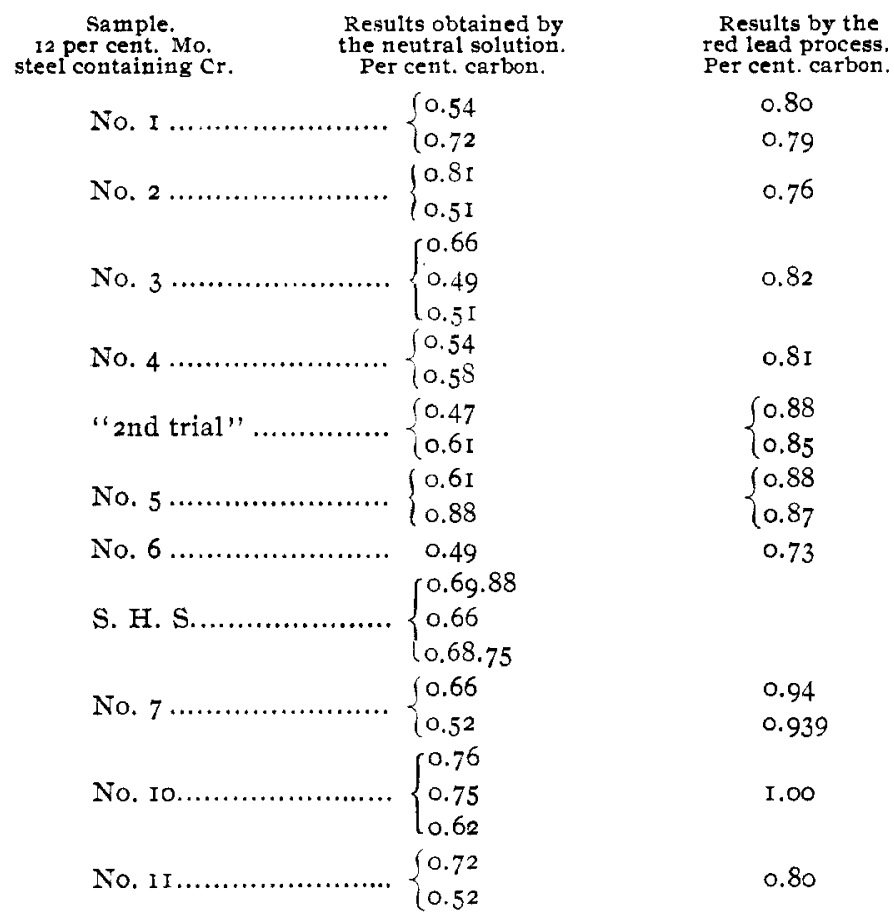

The method was first applied to plain carbon steels, pig iron, and white iron and was found to be perfectly accurate.

After more than eighteen months' daily use of the red lead for the determination of carbon in steel, pig iron, alloy steels and ferro alloys, the details that have been found useful and reliable are as follows:

If the borings are coarse, the thin curly portions of not over I $\mathrm{mm}$. thickness are selected. It is rarely necessary to operate with even this thickness. Not more than 2 grams of such drillings and not less than 4 grams of the red lead are weighed into a glassstoppered $60 \mathrm{cc}$. weighing-bottle. The bottle is then shaken to mix the drillings and lead oxide.

The steel sample submitted for analysis is drilled with a flat or diamond pointed drill. This style of drill will grind many of the drillings to 20-mesh fineness in the case of soft or annealed steels. If the steel be unannealed and of a carbon content ranging from about 0.35 per cent. carbon and higher, thin curly drillings are obtained which decarbonize readily by reason of thinness. 
Care is taken at all times to cover such bulky drillings with the oxide of lead as any drillings that project above the main body of the charge are likely to escape oxidation.

For soft steels and annealed steels two sieves are used. One has a 20-mesh gauze and the other one a 30-mesh gauze. Those drillings that pass the 20-mesh gauze but do not pass the 30-mesh sieve are used for analysis.

This arrangement rejects the fine dust and the thick drillings. When very small pieces of steel are received they are drilled with $3 / 10$ inch diameter twist or straight drills. All sizes of the flat, or diamond point drills are kept at hand from $1 / 4$ inch diameter to $\%$ inch. Any good mill blacksmith can make the flat drills. By these means it is rarely, if ever, necessary to resort to the copper and potassium chloride separation of the carbon. In the laboratory of the Park Steel Co., where from twenty-five to thirtyfive combustions are made each day, covering a range from 0.04 to 3.5 per cent. carbon, the writer does not recall a single instance in a year's time when it was necessary to resort to the double chloride process.

The mixture of lead oxide and drillings is transferred from the weighing-bottle to porcelain boats. The Royal Meissen brand $15 \times 75 \mathrm{~mm}$. or II $2 \times I_{2} \mathrm{~mm}$. is mostly used, being convenient sizes. The porcelain boats are slipped into porcelain tubes of $16 \mathrm{~mm}$. inside diameter $\times 600 \mathrm{~mm}$. long. Two furnaces with their porcelain tubes are operated at the same time. Until recently, the outlet ends of these tubes were filled for a distance of $125 \mathrm{~mm}$. with granulated copper oxide. Later the copper oxide was found to be unnecessary. Oxygen is used during the combustion. It passes through a preheating furnace filled with I $25 \mathrm{~mm}$. of copper oxide, then through a jar containing pieces of caustic potash (Fig. 3). It next bubbles through a solution of potassium hydroxide contained in a safety apparatus (Fig. I) and is then dried in jars of soda-lime and calcium chloride of the design given in Fig. 3. This drying and purifying apparatus can be readily arranged and securely fastened in a space $25^{\circ}$ $\times 406 \mathrm{~mm}$.

The combustions are operated in the usual manner. The portion of the tube containing the copper oxide is heated to redness, and then the remainder of the tube lying within the furnace is brought to the same temperature. The combustion tubes are constantly 
kept hot through half the length so that the combustion commences almost as soon as the stoppers are inserted. While the boats are being charged the oxygen is passing slowly through the

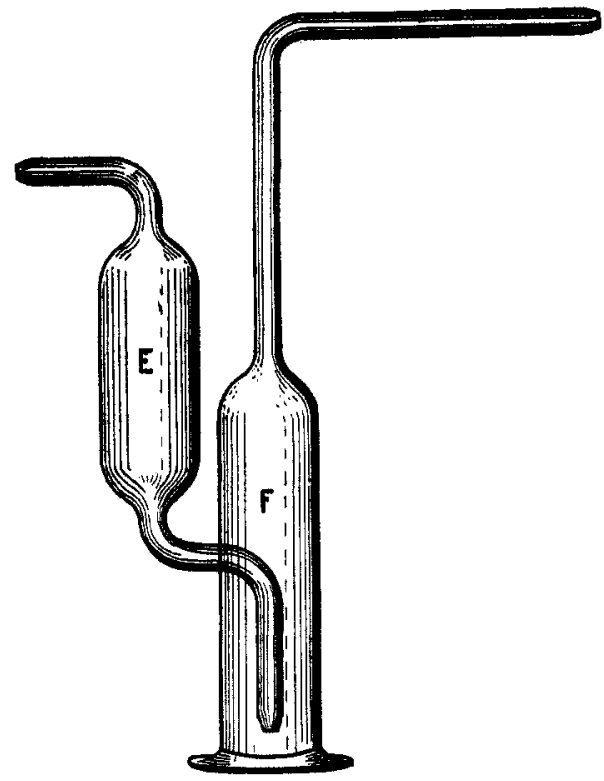

Fig. I.

tubes and the weighing and absorbing apparatus which has been previously weighed and attached. (This weighing apparatus is shown in Fig. 2. It was designed by the writer as a substitute for the different forms of potash bulbs now in the market. It is made of heavy glass. It is easily kept clean, is not top-heavy, and does not occupy much space in a balance case.) As soon as the steel begins to burn there is, at first, a rapid evolution of gas which quickly ceases. More oxygen is then tumed into the apparatus from the steel cylinder so that a very slow bubbling is maintained through the weighing apparatus. When the oxidation of the charge is completed, the oxygen begins to rush through the apparatus at a high rate of speed. The flow of the gas is quickly checked to a normal rate, that is, it is checked so that, as it leaves the preheater, it passes through the safety apparatus (Fig. I) at a rate of about 26 bubbles per ten seconds. The stream is evenly distributed to the two combustion tubes by means of a Y-tube and screw pinch-cocks. The stream passes 
through the weighing apparatus (Fig. 2) at the rate of $250 \mathrm{cc}$. every ten minutes which is the normal speed. When the com-

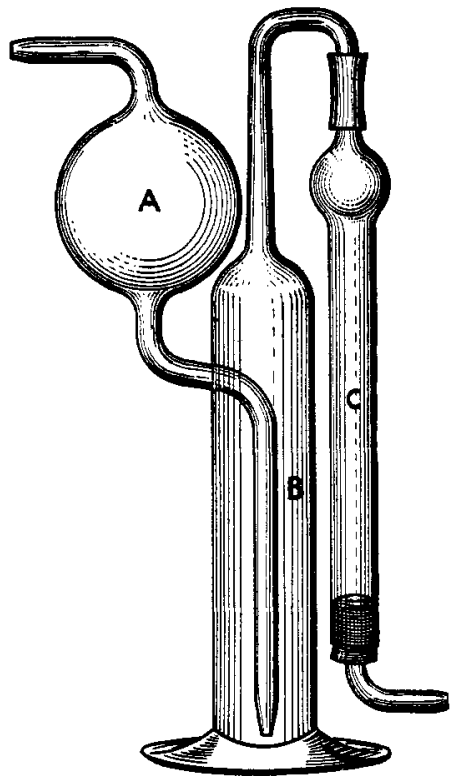

Fig. 2.

bustions are completed in both sets of apparatus, as indicated by the passage of the gas at a high rate of speed, the normal is then maintained through the red hot tubes ten minutes longer to insure complete oxidation and that all of the carbon dioxide has been carried to the weighing apparatus. The products of the combustion pass through a purifying train shown in Fig. 4 . The train connects with the glass tube leading from the outlet end of the porcelain combustion tube, by means of heavy combustion rubber tubing, at $H$. The gases pass through the cylinder (I) which contains a column of granulated zinc of 20mesh fineness. The use of granulated zinc to remove acid and chlorine in carbon combustions was first suggested by Dr. Edward $\mathrm{S}$. Johnson. Cylinder I is $254 \times \mathrm{I}_{3} \mathrm{~mm}$. The zinc is held in place with plugs of glass wool. The gases next enter a cylinder (J) which contains a column of phosphoric anhydride. The phosphoric anhydride powder is held in place with plugs of ignited asbestos. Cylinder $\mathrm{J}$ is $178 \times \mathrm{I}_{3} \mathrm{~mm}$. Glass wool plugs should 
not be used in $\mathrm{J}$ as they become clogged after a few combustions. Ignited asbestos is free from this objection.

The carbon dioxide, which is now freed from litharge and any acid fumes by zinc and from any moisture by the phosphoric anhydride, enters the weighing apparatus $(L)$. This weighing

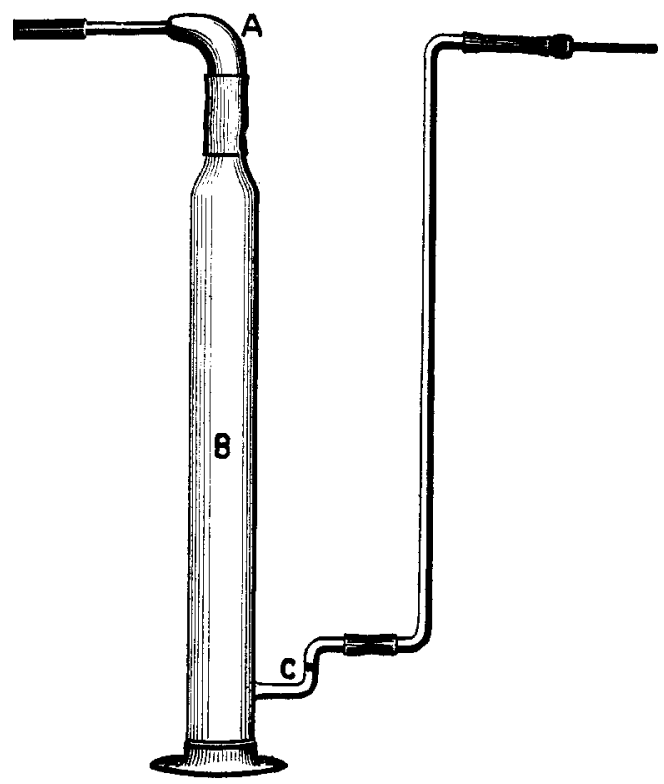

Fig. 3.

apparatus, as shown in the complete train (Fig. 4), differs slightly from the writer's first design shown in Fig. 2. The apparatus is charged with $20 \mathrm{cc}$. of potassium hydroxide consisting of one part of caustic potash dissolved in two parts of water. The drying tube (C) is filled with small pieces of $d r y$ caustic potash obtained by quickly cracking dry sticks of caustic potash in a porcelain mortar. Each end of the drying tube (C) contains a plug of asbestos or glass wool. Before inserting the rubber stopper in C care must be taken to free the surface of the tube (C) from any moist caustic potash as potassium hydroxide causes decomposition of rubber, resulting in continuous loss of weight.

The weighing apparatus is ready for recharging at the end of the fortieth combustion. The tare is then used for the absorbing and weighing of the carbon dioxide obtained from the next forty combustions, the exhausted apparatus now constituting the tare. 


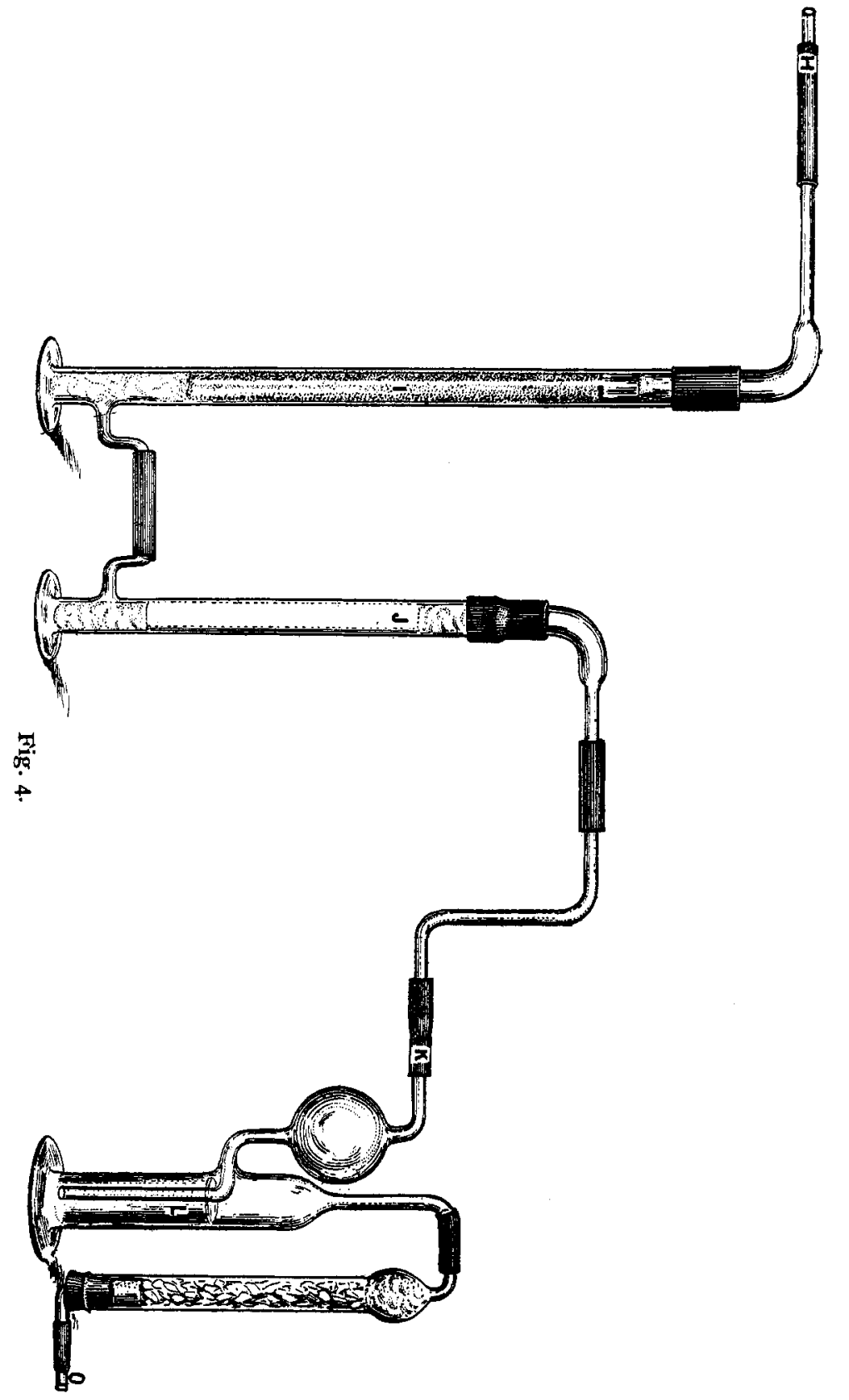


During the passage of the oxygen and the subsequent aspiration of the weighing apparatus to remove any oxygen present, the outlet, (O) Fig. 4, is protected from the ingress of moisture or impure air by a guard tube filled with small pieces of caustic potash. This guard tube is not shown in Fig. 4. All parts of the apparatus shown in Fig. 4 are connected by heavy-wall pure rubber tubing.

When the combustions are completed the weighing apparatus is detached from its train and the outlet of the train is closed with a glass plug. The weighing apparatus from each train is then connected to a tower, of the style shown in Fig. 3, which is filled with small pieces of caustic potash. Air is then drawn through this tower into the weighing apparatus for ten minutes to remove oxygen. The apparatus and its tare are next carefully wiped with a clean linen handkerchief and are placed in the balance case for weighing. The inlet and outlet of the weighing apparatus are kept closed with rubber caps except during weighings or when attached in the train (Fig. 4).

The method of using an exact duplicate of the weighing apparatus for a tare exposes the same amount of surface to the air during weighings and avoids the use of the larger weights.

Single combustions by this process have been made in this laboratory in fifty-five minutes.

As previously stated the porcelain tubes are kept red hot throughout one-half their length night and day so that the combustion commences in a minute or two after the boat is inserted and the combustion tube is stoppered. The remaining burners are lighted immediately after the tube is closed.

The red lead used in this work must be thoroughly mixed and ground free of lumps before its carbon content is determined. The so-called pure red lead costing about 9 cents per pound in fifty-pound lots is found satisfactory for the purpose. Blank combustions with 4 grams of red lead are at present yielding $6 \mathrm{mg}$. of carbon dioxide which are deducted from each determination. Blank combustions or analyses of standard steels should be made each day. The red lead is kept in tightly stoppered bottles.

The method of weighing the carbon dioxide obtained in the red lead combustions as barium carbonate was tried for several months. As it is not necessary to dry the carbon dioxide in this 
modification of the red lead method, the carbon dioxide was passed through a cylinder illustrated by Fig. 3 filled with granulated zinc to remove litharge fumes, and from thence the carbon dioxide entered the absorbing apparatus which consisted of two $254 \times 25.4 \mathrm{~mm}$. test-tubes connected in tandem and containing barium hydroxide solution. The solution in the first tube converts the bulk of the carbon dioxide formed into barium carbonate but in the higher carbon steels a little escapes into the second tube.

The barium carbonate is filtered through $12-\mathrm{cm}$. filters reinforced at the apex by a piece of cheese-cloth. The precipitate is washed thirty times with distilled water, allowing each washing to be drawn off by slight suction.

The cheese-cloth is removed and the precipitate is ignited and weighed. From this weight the amount of barium carbonate formed from the impurities in the red lead and that obtained from the unavoidable exposure of the excess of the hydroxide during filtration and washing is deducted. From the net weight of barium carbonate the percentage is calculated.

The barium hydroxide solutions are prepared by dissolving, or nearly dissolving, 200 grams of barium hydroxide crystals in four liters of water. It is filtered by suction through a paper pulp filter and preserved with the usual precautions. The test-tubes for the solution are provided with $30 \mathrm{cc}$. and $70 \mathrm{cc}$. marks. The pair of tubes constituting the absorption pair are filled to the $30 \mathrm{cc}$. marks with water and the barium hydroxide solution is then poured in until the $70 \mathrm{cc}$. marks are reached.

A protracted comparison of the two gravimetric processes described in this paper extending over a period of several months was made. The method whereby the resultant carbon dioxide was weighed as barium carbonate checked excellently with the one in which the carbon dioxide was absorbed and weighed in the apparatus shown in either Fig. 2 or in the termination of the train, Fig. 4, agreeing within o.oI per cent. or less. The latter process is preferred as requiring less manipulation, less oxygen, and less time. In the barium carbonate method it was necessary to force the oxygen through the safety apparatus (Fig. I) at the rate of 38 bubbles per ten seconds on account of the resistance to the passage of the gas through the absorption test-tubes. 
The ordinary ten-burner Bunsen combustion furnace is employed but with certain alterations to secure higher heating power. At the points where the porcelain tubes rest in the ends of the furnace these ends are slotted down about $25 \mathrm{~mm}$. This permits the tubes to lie well enveloped with the flames. Further, under each foot of the furnaces pieces of fire-brick about $28 \mathrm{~mm}$. thick are placed. Also the rows of burners are lowered until they rest on the laboratory table. To keep the rows vertical one burner at each end of the rows is wired to the furnace. This lowering of the burners and raising of the furnace frame, by use of the fire-brick, improves the draught and secures hot flames with a minimum gas pressure. Clay gutters are placed under the porcelain tubes to prevent sudden cooling. Strips of wet blottingpaper about $25 \mathrm{~mm}$. wide are wrapped around the ends of the porcelain tubes to keep the rubber stoppers from burning. The ends of these strips dip into suitable vessels of water.

Porcelain tubes glazed inside only, of $16 \mathrm{~mm}$. inside diameter by $600 \mathrm{~mm}$. long, will last from six weeks to two months when in use night and day. Flames are always kept under the tubes. Such tubes cost about \$r. 80 each.

Porcelain boats are cleaned for further use by allowing them to stand in nitric acid of $1.20 \mathrm{sp}$. gr. for some hours. The boats are ignited a few minutes in the flame of a Bunsen burner just before being used. Porcelain boats $14-15 \mathrm{~mm}$. wide by $70-75 \mathrm{~mm}$. long, Royal Meissen brand, are quoted in ten-gross lots at $\$_{14} .50$ per gross. These boats can be used three times.

The apparatus shown in Fig. I was designed as a safety apparatus to prevent the potassium, hydroxide solution from blowing over into the rubber tubing from any cause. The oxygen, as it leaves the preheating furnace, enters the chamber $\mathrm{E}$ and bubbles through chamber $F$ which is filled to one-third its capacity with potassium hydroxide solution consisting of one part of caustic potash dissolved in two parts of water. F is $35 \mathrm{~mm}$. outside diameter by $170 \mathrm{~mm}$. long. Fig. 3 shows a tower or jar that is used as a container for small pieces of stick caustic potash for purifying the oxygen. The pieces of apparatus shown in Figs. I, 3 and 4 were designed by the writer to avoid the use of rubber stoppers.

The following results attest the accuracy of the red lead process: 


Weight of of lead
sample oxide
Nakent. used.
Grams. Grams.

S. S. Co. carbon steel................... 3

$3 \quad 9$

No. 690.

9

No. 350 , tungsten steel.

0.395

0.415

0.985

0.96

I. 285 I. 29

No. 353 , tungsten steel.

I. 338

I.354

0.698

0.696

No. 22, high per cent. nickel steel...

0.447

No. 14, nickel steel.

$\{2.40$

$\{2.39$

0.450

S XIX, high per cent. tungsten steel

Wash metal

$1 / 2$

$I^{1 / 2} \quad\left\{\begin{array}{l}3.56 \\ 3.65\end{array}\right.$

Wash metal $I^{3 / 2}$

C. B. pig meta $I^{1 / 2}$

C. B. pig metal. $I^{1 / 2}$

Soft O. H. steel No. 6

Soft O. H. steel No. 2

$6 \quad 3$

3

3.65

2.35

3.59

Soft O. H. steel No. $376 \mathrm{r}$

8

6

$3.5^{8}$

4.01

$I^{3 / 2} \quad 4.04$

4.04

0.185

4

0.097

0.077

$0.15^{6}$

0.145

In July, I9oI, a sample of steel was sent by Sanderson Bros. Steel Works to several laboratories. The writer retained a portion of these drillings for several years. The different laboratories reported as follows:

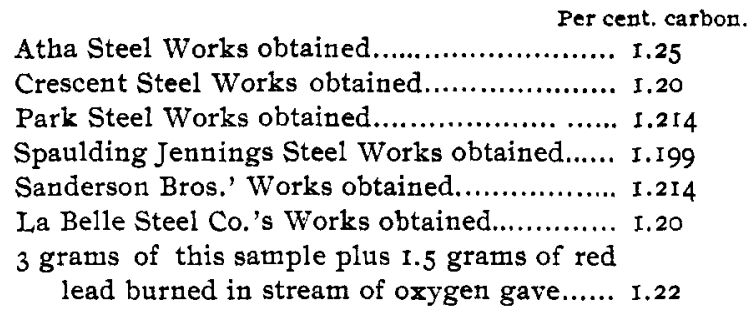

In March, Igor, the following parties reported the carbon of another sample of steel:

Per cent. carbon.

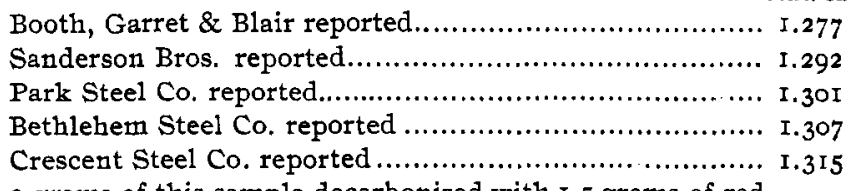

3 grams of this sample decarbonized with 1.5 grams of red lead yielded. I.305

The writer has since had occasion to compare results with other laboratories covering a range in carbon from 0.32 to $\dot{I} .45$ per cent. carbon with equally good agreements. 


\section{CARBON IN FERRO-CHROMIUM.}

In applying the red lead process to ferro-chromium, it was found that the maximum carbon in the 65 per cent. chromium alloy was obtained by burning the alloy with three to four times its weight of red lead.

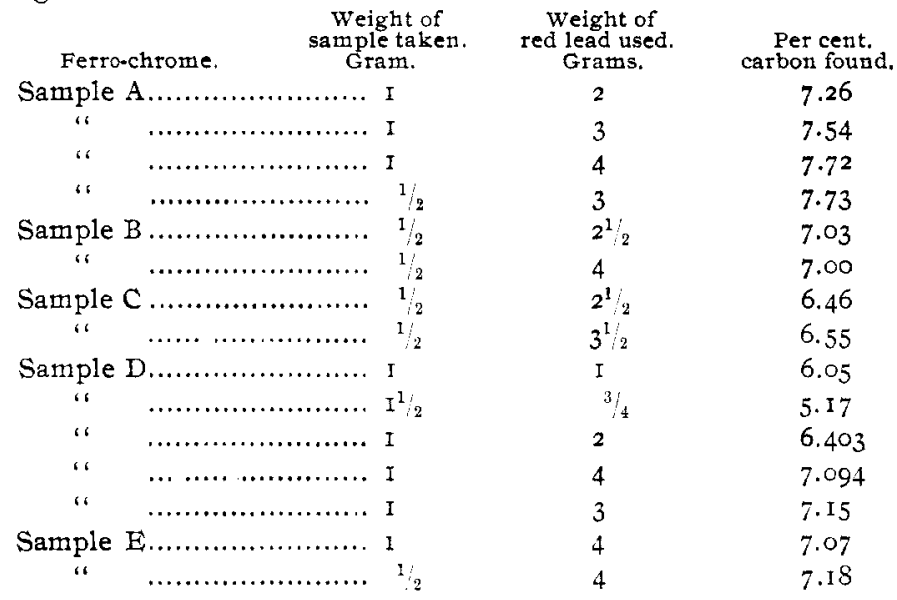

In February, 1906, the copper oxide was omitted from one combustion tube. The space ordinarily occupied with copper oxide was filled, loosely, with ignited asbestos. The following results indicate that the use of copper oxide in combustions with red lead is unnecessary:

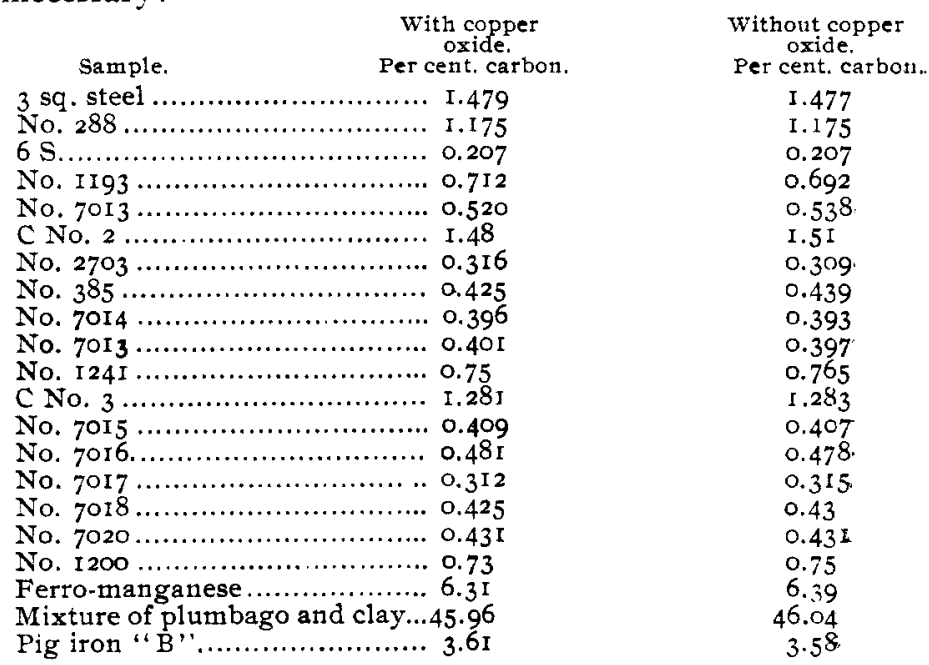


The omission of copper oxide would permit the use of shorter porcelain tubes and shorter combustion furnaces. A red hot body of copper oxide hastens breakage of porcelain tubes by causing unequal cooling strains when the furnace flames are lowered or extinguished for any reason. Since February one tube has been in use without copper oxide. The oxide is still retained in the companion tube so that daily comparisons have been made.

LABORATORY OF THE PARK STEEL WORKS,

Crucible steel Co. of America, Pittsburg, Pa, April 26, 1906.

\section{THE NITROMETER.}

By J. NEWField aNd J. S. MARX.

Received February I2, I906.

Having occasion to use the nitrometer extensively in our work we have made a study of some of the factors which affect the results obtained by means of this instrument, especially with reference to its use in the analysis of nitrocellulose and other explosives. We have used the form known as Lunge's Improved Nitrometer or Gas Volumeter.

A description of this apparatus is very well given in Sutton's "Volumetric Analysis," eighth edition, pages 6I6 to 6I8. It consists in brief of a decomposing bulb connected by a heavy rubber tube to an overflow. By means of a small piece of rubber tubing this bulb can be connected to a long measuring tube graduated to tenths of cubic centimeters. Temperature and barometric corrections are dispensed with by having a closed tube inserted between the measuring tube and its overflow, all three being joined together by means of a rubber tube. In this sealed tube are $100 \mathrm{cc}$. of air over mercury at $760 \mathrm{~mm}$. pressure and $0^{\circ} \mathrm{C}$. temperature. Thus when the volume of air in the tube is Ioo cc. and the mercury column leveled with that in the measuring tube, its gas is also under the same conditions of temperature and pressure.

However, it would be difficult and also unnecessary to obtain just roo cc. of air in the sealed tube under standard conditions, so a factor is obtained in the following way: Approximately roo cc. of air are introduced into the sealed tube, then a weighed portion of perfectly pure, dry potassium nitrate is run through the apparatus. From its composition I gram of the nitrate gives 22 I cc. of nitric oxide gas, under normal conditions. The differ- 